\title{
NOTA
}

\section{EFEITO RESIDUAL DO LODO DE ESGOTO NA PRODUTIVIDADE DO MILHO SAFRINHA ${ }^{(1)}$}

\author{
Graziela Moraes de Cesare Barbosa ${ }^{(2)}$, João Tavares Filho ${ }^{(3)}$, Osmar \\ Rodrigues Brito $^{(3)}$ \& Inês Cristina Batista Fonseca ${ }^{(3)}$
}

\begin{abstract}
RESUMO
Das opções de disposição final do lodo de esgoto, a reciclagem agrícola tem sido uma das mais utilizadas em diversos países desenvolvidos, sendo considerada a forma mais adequada em termos técnicos, econômicos e ambientais. Este trabalho teve por objetivo avaliar o efeito residual do lodo de esgoto na produtividade do milho safrinha, após dois anos de aplicação consecutiva desse resíduo em um Latossolo Vermelho eutroférrico. O experimento foi realizado em campo, em delineamento em blocos ao acaso com três repetições, e os tratamentos foram os seguintes: testemunha e adubações com lodo de esgoto nas doses de 6, 12, $24 \mathrm{e}$ $36 \mathrm{t} \mathrm{ha}^{-1}$ (peso de matéria seca). Houve efeito residual do uso do lodo de esgoto caleado na produtividade de milho safrinha; a dose de $36 \mathrm{t} \mathrm{ha}^{-1}$ foi estatisticamente superior às doses de $6 \mathrm{e} 12 \mathrm{t} \mathrm{ha}^{-1}$.
\end{abstract}

Termos de indexação: biossólidos, adubo orgânico, fertilizante.

\section{SUMMARY: RESIDUAL EFFECT OF SEWAGE SLUDGE ON OFF-SEASON CORN YIELD}

Among the possibilities of final disposal of sewage sludge, agricultural recycling has become one of the most widely used in several developed countries, and is considered the most appropriate in technical, economical and environmental terms. This study aimed at evaluating the sewage sludge residual effect on off-season corn yield on an Eutroferric Red Latossol (Oxisol). The field experiment was in a randomized block design with three replications, with treatments consisting of increasing doses of sewage sludge $(0,6,12,24$ and $36 \mathrm{th} \mathrm{ha}^{-1}$, on a dry weight basis), applied in the two previous cropping seasons.. The residual effect of the application of lime-stabilized sewage sludge increased the yield of off-

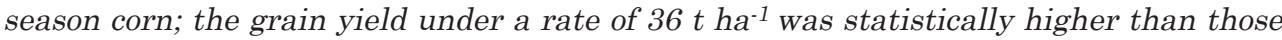
under 6 and $12 \mathrm{tha}^{-1}$.

Index terms: biosolids, organic fertilizer, fertilizer.

\footnotetext{
(1) Parte da Tese de Doutorado apresentado pelo primeiro autor para obtenção do título de Doutor em Agronomia pela Universidade Estadual de Londrina - UEL. Recebido para publicação em maio de 2005 e aprovado em março de 2007.

${ }^{(2)}$ Doutoranda em Agronomia da Universidade Estadual de Londrina - UEL. Caixa Postal 6001, CEP 86051-990 Londrina (PR). Bolsista do CNPq. E-mail: obarbosa@sercomtel.com.br

(3) Professores do Departamento de Agronomia, UEL. E-mail: tavares@uel.br
} 


\section{INTRODUÇÃO}

Dentre as opções de disposição final do lodo de esgoto, sua utilização em áreas agrícolas tem sido uma solução considerada viável do ponto de vista econômico e ambiental. Desde 1927, esse material vem sendo usado como fertilizante nos Estados Unidos (Marques, 1996). Recentemente, cerca de $25 \%$ de todo o lodo de esgoto produzido naquele País era aplicado na agricultura (Tsutiya, 1999).

As propriedades do lodo de esgoto são semelhantes às de outros produtos orgânicos comumente usados na agricultura, como os estercos suíno, bovino e avícola. Contudo, no Paraná, segundo Sanepar (1997), por questão de segurança sanitária, não se recomenda o uso desse material na horticultura e para os cultivos com produtos consumidos crus e que tenham contato direto com o lodo de esgoto, sendo indicado para culturas com milho, trigo, cana-de-açúcar e sorgo, devido às melhores respostas apresentadas.

Alguns pesquisadores demonstraram que doses de lodo caleado melhoram as condições químicas e físicas do solo, promovendo aumento de $\mathrm{pH}, \mathrm{CTC}, \mathrm{V} \%$, teores

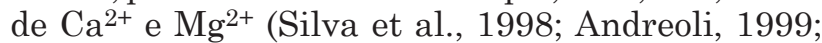
Barbosa et al., 2002a), formação de agregados, aumento da condutividade hidráulica e porosidade (Andreoli \& Pegorini, 2000; Barbosa et al., 2002b). Biscaia \& Miranda (1996) avaliaram a importância da adição de lodo para o incremento potencial produtivo do solo e a nutrição das plantas, permitindo a elevação da produtividade.

Andreoli (1999) observou que, com elevação do pH pela adição do lodo caleado, a produtividade foi reduzida, em razão de o estoque de $\mathrm{N}$ no sistema solo-planta apresentar níveis muito acima do necessário. Portanto, o $\mathrm{pH}$ inicial do solo representa um dos fatores que devem ser considerados como limitante de dosagens para o lodo caleado.

Nesse contexto, o lodo de esgoto tem sido estudado como fertilizante na produção de várias culturas, dentre elas o milho, mostrando resultados positivos da aplicação do material (Lourenço et al., 1995; Biscaia \& Miranda, 1996; Pereira et al., 1997; Silva et al., 2002). Trabalhando em um Latossolo Vermelho eutroférrico, Andreoli (1999) verificou maior produção de milho em tratamentos onde foi utilizado lodo de esgoto caleado na dose de $18 \mathrm{tha}^{-1}$, em relação àqueles com adubação mineral e à testemunha.

Com base no exposto, este trabalho teve por objetivo avaliar o efeito residual da aplicação de lodo de esgoto caleado na produtividade do milho safrinha em um Latossolo Vermelho eutroférrico.

\section{MATERIAL E MÉTODOS}

O trabalho foi realizado em um Latossolo Vermelho eutroférrico (teor de argila variando de 760 a $820 \mathrm{~g} \mathrm{~kg}^{-1}$ entre 0 e $0,40 \mathrm{~m}$ ), localizado no município de Londrina (PR), com coordenadas geográficas de $23^{\circ}$ 23 ' de latitude $\mathrm{S}$ e $51^{\circ} 11$ ' de longitude W. A altitude média do local é de $566 \mathrm{~m}$, e o clima, subtropical úmido, segundo classificação de Köppen, do tipo Cfa.

Este experimento iniciou-se em 1996 (Andreolli, 1999), quando foram determinadas as características químicas do solo (Quadro 1).

O lodo utilizado (Quadro 2) foi digerido anaerobiamente e produzido em estação do tipo Reator Anaeróbio de Lodo Fluidizado-RALF. O material foi tratado com cal (dolomítica) na dose de $50 \%$ do peso de lodo seco. A umidade original do lodo variava entre 50 e $75 \%$, o que se mostrou favorável ao processo de calagem manual.

$\mathrm{Na}$ implantação do experimento (1996), as quantidades de calcário e complementação mineral (formulação 8-18-16) foram determinadas com base na análise do solo e do lodo.

O delineamento experimental utilizado foi em parcelas subdivididas no tempo. As parcelas foram divididas em blocos, com cinco tratamentos e três repetições, totalizando 15 parcelas experimentais (240 $\mathrm{m}^{2}$ cada parcela). Os seguintes tratamentos foram testados: T1 - testemunha; T2 - $6 \mathrm{t} \mathrm{ha}^{-1} \mathrm{ano}^{-1} \mathrm{de}$ lodo caleado; T3 - $12 \mathrm{t} \mathrm{ha}^{-1} \mathrm{ano}^{-1}$; T4 - $24 \mathrm{t} \mathrm{ha}^{-1} \mathrm{ano}^{-1} \mathrm{e}$ T5 - 36 t ha $^{-1}$ ano $^{-1}$.

Quadro 1. Características químicas de um Latossolo Vermelho eutroférrico antes da aplicação de calcário, adubo e lodo de esgoto caleado

\begin{tabular}{|c|c|c|c|c|c|c|c|c|c|c|}
\hline Profundidade & $\mathbf{p} \mathbf{H}^{(1)}$ & $\mathbf{H}+\mathbf{A l}$ & $\mathrm{Ca}^{2+}$ & $\mathrm{Mg}^{2+}$ & $\mathbf{K}^{+}$ & CTC & $\mathbf{P}$ & C & $\mathbf{m}^{(2)}$ & $\mathrm{V}^{(3)}$ \\
\hline $\mathrm{cm}$ & & 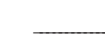 & 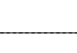 & $\mathrm{nol}_{\mathrm{c}} \mathrm{dm}$ & & 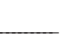 & $\mathrm{mg} \mathrm{dm}^{-3}$ & $\mathrm{~g} \mathrm{dm}{ }^{-3}$ & 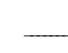 & - \\
\hline $0-20$ & 4,8 & 5,7 & 3,6 & 1,5 & 0,41 & 11,2 & 10 & 19 & 3,5 & 49,2 \\
\hline $20-40$ & 4,9 & 5,3 & 3,2 & 1,7 & 0,12 & 10,3 & 2 & 14,3 & 3,8 & 48,6 \\
\hline
\end{tabular}

${ }^{(1)} \mathrm{pH} \mathrm{H}_{2} \mathrm{O} .{ }^{(2)} \mathrm{m}$ : saturação por alumínio. ${ }^{(3)} \mathrm{V}$ : saturação por bases.

Fonte: Andreoli (1999). 
Quadro 2. Características químicas de uma amostra de lodo (antes da caleação) anaeróbio (RALF) utilizado na área experimental

\begin{tabular}{|c|c|c|c|c|c|c|c|c|}
\hline pH $\mathrm{H}_{2} \mathrm{O}$ & $\mathrm{P}_{2} \mathrm{O}_{5}$ total & $\mathbf{K}_{2} \mathbf{O}$ & $\mathrm{Ca}^{2+}$ & $\mathbf{M g}^{2+}$ & $\mathrm{N}$ total & MO total & C total & $\mathrm{C} / \mathrm{N}$ \\
\hline 6,1 & 9,5 & 3,4 & 8,3 & 3,0 & 22,2 & 362,0 & 201,0 & $9 / 1$ \\
\hline
\end{tabular}

Fonte: Andreoli (1999).

Após a aplicação do calcário e complementação mineral, o solo foi gradeado $(20 \mathrm{~cm})$, sendo o lodo de esgoto aplicado manualmente nas doses anuais de 6 , 12, 24 e $36 \mathrm{t} \mathrm{ha}^{-1}$ (peso de matéria seca). Estas doses foram aplicadas uma vez por ano, durante dois anos consecutivos. Após cada aplicação do lodo de esgoto caleado, efetuou-se uma segunda gradagem, para sua incorporação. Durante os dois anos de cultivo (19961997 e 1997-1998) foram implantadas as culturas de aveia e milho, nas safras de inverno/verão, respectivamente. Depois desses dois anos de cultivo e da colheita do milho (safra verão), cessou-se a aplicação de lodo de esgoto.

Iniciou-se, então, a implantação da cultura de milho safrinha para avaliação da produtividade, considerando o efeito no residual do lodo de esgoto caleado (março/1999). Novamente, foram coletadas amostras $(0,0-0,20 \mathrm{~m})$ de solo de todas as parcelas, para análise química, e determinados o $\mathrm{pH}\left(\mathrm{CaCl}_{2} 0,01 \mathrm{~mol} \mathrm{~L}^{-1}\right)$, $\mathrm{Ca}\left(\mathrm{KCl} 1 \mathrm{~mol} \mathrm{~L}^{-1}\right), \mathrm{Mg}\left(\mathrm{KCl} 1 \mathrm{~mol} \mathrm{~L}^{-1}\right), \mathrm{K}$ (Mehlich-1), P (Mehlich-1) e C orgânico (Walkley-Black), segundo método da Embrapa (1997).

Para avaliação da produtividade do milho safrinha (julho/99), foram coletadas, aleatoriamente, 20 espigas/parcela nas três fileiras centrais, colocadas em sacos de papel para, posteriormente, ser debulhadas e secas, corrigindo-se a umidade dos grãos para $13 \%$. $\mathrm{O}$ peso das sementes foi obtido pelo método da pesagem direta das amostras com mil sementes (Brasil, 1980).

Os dados da análise química foram submetidos à análise de variância, e a comparação de médias foi feita pelo teste de Tukey. Quanto à determinação da maior produtividade do milho safrinha, considerando a melhor dose residual de lodo de esgoto caleado, fezse a análise de variância, complementada pelo teste de Tukey e regressão polinomial.

\section{RESULTADOS E DISCUSSÃO}

Primeiramente, foi necessário avaliar e comparar os resultados da análise química do solo (Quadro 3), efetuada após 15 dias do plantio do milho safrinha (sobre o resíduo do lodo de esgoto caleado), bem como os dados obtidos da análise química deste solo, antes da correção com calcário, adubação complementar e aplicação do lodo de esgoto caleado (Quadro 1). Podese observar que, mesmo após a colheita do milho da safra de verão (fev./1999) e emergência do milho safrinha, as parcelas que receberam o lodo de esgoto caleado apresentaram aumentos significativos nos teores de $\mathrm{Ca}^{2+}, \mathrm{Mg}^{2+}$, $\mathrm{pH}$ e $\mathrm{C}$ orgânico, aumentando conseqüentemente a CTC e V \%.

Os valores de $\mathrm{K}$ não apresentaram diferença significativa em relação à testemunha, em razão de o lodo ser deficiente neste elemento. Vários autores recomendam a suplementação mineral potássica quando for utilizado somente o lodo de esgoto caleado como adubação complementar (Da Ros et al., 1993; Oliveira et al., 1995; Silva et al., 1998).

A adição da MO é de fundamental importância para a manutenção do potencial produtivo do solo, por isso a possibilidade do aumento do C orgânico proporcionada pela adição do lodo tem efeito positivo nas propriedades químicas e físicas e, conseqüentemente, na produtividade do milho. O lodo de esgoto promove o aumento de cargas negativas devido à sua alta concentração de $\mathrm{MO}$, além de enriquecer o meio

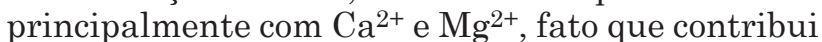
para o aumento da CTC e V \% (Stevenson, 1982; Melo et al., 1994; Silva et al., 1995).

A curva representativa de produtividade (Figura 1), considerando doses aplicadas de lodo de esgoto, pode ser representada pela regressão polinomial de segundo grau, expressa pela equação $\hat{y}$ $=2483,3+286,51 \mathrm{x}-14,87 \mathrm{x}^{2}+0,2332 \mathrm{x}^{3}\left(\mathrm{R}^{2}=0,929\right)$. Dentro do espaço experimental avaliado, todos os tratamentos que utilizaram o lodo de esgoto mostraram maior produtividade que a da testemunha. Isso parece indicar que o lodo de esgoto pode manter a produtividade do milho safrinha em níveis satisfatórios após uma safra normal sem a contribuição de outro insumo, evidenciando seu efeito residual. Dados semelhantes foram constatados por Silva et al. (2002), os quais, ao estudarem o efeito residual nas parcelas com doses de lodo de esgoto com e sem calcário e nos tratamentos com adubação química, verificaram que a dose utilizada $\left(54 \mathrm{t} \mathrm{ha}^{-1}\right)$ teve efeito residual até o terceiro ano após a aplicação do lodo, com produtividade média de $4.700 \mathrm{~kg} \mathrm{ha}^{-1}$ de grãos de milho. Os resultados de produção de milho obtidos 
Quadro 3. Resultados da análise química do solo, para amostras coletadas 15 dias após o plantio do milho safrinha, na profundidade de 0-0,20 m, em Latossolo Vermelho eutroférrico

\begin{tabular}{|c|c|c|c|c|c|c|c|c|}
\hline Tratamento & $\mathbf{p H ~} \mathrm{CaCl}_{2}$ & $\mathrm{Ca}^{2+}$ & $\mathrm{Mg}^{2+}$ & $\mathbf{K}^{+}$ & CTC efetiva & $\mathbf{P}$ & $\mathbf{V}$ & $\mathbf{C}$ \\
\hline & & \multicolumn{4}{|c|}{$\mathrm{cmol}_{\mathrm{c}} \mathrm{dm}^{-3}$} & $\mathrm{mg} \mathrm{dm} \mathrm{m}^{-3}$ & $\%$ & $\mathrm{~g} \mathrm{dm} \mathrm{m}^{-3}$ \\
\hline Testemunha & $5,30 \mathrm{~d}^{1}$ & $4,30 \mathrm{~b}$ & $2,31 \mathrm{c}$ & $0,32 \mathrm{a}$ & $12,16 \mathrm{~b}$ & $3,66 \mathrm{~b}$ & $57,31 \mathrm{~d}$ & $18,88 \mathrm{ab}$ \\
\hline $6 \mathrm{t} \mathrm{ha}^{-1}$ & $5,63 \mathrm{~cd}$ & $4,70 \mathrm{~b}$ & $2,50 \mathrm{c}$ & 0,16 a & $12,15 \mathrm{~b}$ & $2,26 \mathrm{~b}$ & $61,15 \mathrm{~cd}$ & $16,08 \mathrm{~b}$ \\
\hline $12 \mathrm{ha}^{-1}$ & $6,08 \mathrm{bc}$ & $5,76 \mathrm{ab}$ & $3,28 \mathrm{bc}$ & 0,19 a & $12,49 \mathrm{~b}$ & $3,42 \mathrm{~b}$ & $73,53 \mathrm{bc}$ & $21,10 \mathrm{ab}$ \\
\hline $24 \mathrm{ha}^{-1}$ & $6,36 \mathrm{ab}$ & $6,58 \mathrm{a}$ & $4,31 \mathrm{ab}$ & $0,34 \mathrm{a}$ & $14,06 \mathrm{ab}$ & $9,77 \mathrm{a}$ & $79,75 \mathrm{ab}$ & $26,46 \mathrm{ab}$ \\
\hline $36 \mathrm{ha}^{-1}$ & 6,65 a & 7,28 a & $5,71 \mathrm{a}$ & $0,32 \mathrm{a}$ & 15,85 a & $14,33 \mathrm{a}$ & $84,03 \mathrm{a}$ & 29,95 a \\
\hline CV (\%) & 4,89 & 19,33 & 29,99 & 44,22 & 11,99 & 70,81 & 10,67 & 31,23 \\
\hline
\end{tabular}

(1) Médias seguidas de mesma letra minúscula na coluna não diferem entre si pelo teste de Tukey a $5 \%$.

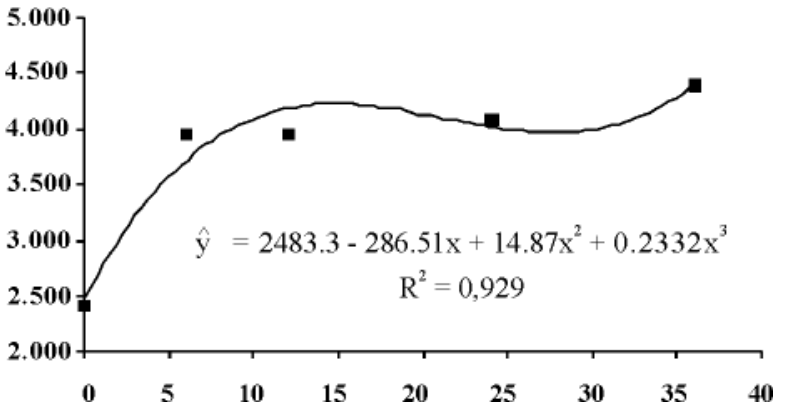

Figura 1. Produtividade de milho safrinha em Latossolo Vermelho eutroférrico, considerando as doses de lodo.

neste estudo estão de acordo com os de vários autores em trabalhos com lodo de esgoto (Lessin \& Garcia, 1979; Hornick, 1982; Lourenço et al., 1996).

Pereira Jr. et al. (1997) constataram que doses de lodo de esgoto promoveram aumento na produtividade do milho, obtendo os melhores rendimentos de grãos com doses iguais ou superiores a $6 \mathrm{t} \mathrm{ha}^{-1}$; também Silva et al. (2000) observaram aumento na produtividade de milho com a utilização de doses de 6 , 12 e $24 \mathrm{t} \mathrm{ha}^{-1}$ de lodo (base seca) como fertilizante para milho, comparando-o a uma testemunha (sem qualquer adubação) e a uma fonte tradicional de suprimento de P (superfosfato triplo). Esses últimos autores concluíram que, nos três anos estudados, houve aumento significativo na produtividade do milho (média de $6.199 \mathrm{~kg} \mathrm{ha}^{-1}$ ) nas parcelas que utilizaram o lodo de esgoto em relação à testemunha e à adubação com P.

Trabalhando em Latossolo Vermelho e doses de 20 a $80 \mathrm{Mg} \mathrm{ha}^{-1}$ durante quatro anos, verificaram-se aumentos lineares de produção de milho com adição de lodo de esgoto, confirmando resultados de Higgins (1994) e Rappaport et al. (1988). Biscaia \& Miranda (1996) compararam as doses de 2, 4, 6 e $60 \mathrm{t} \mathrm{ha}^{-1} \mathrm{de}$ lodo (base seca), obtendo produtividades médias para a cultura de milho acima de $4.000 \mathrm{~kg} \mathrm{ha}^{-1}$, que estão acima da média nacional, a qual, segundo Teixeira (2004), é de $3.534 \mathrm{~kg} \mathrm{ha}^{-1}$. Isso parece indicar que a maior disponibilidade de nutrientes no solo, proporcionada pela aplicação do lodo de esgoto caleado, tem a vantagem de melhorar o crescimento de planta de milho safrinha, com maior produção de matéria seca e, conseqüentemente, aumento da produtividade.

\section{CONCLUSÃO}

Houve efeito residual do uso do lodo de esgoto caleado na produtividade de milho safrinha; a dose de $36 \mathrm{t} \mathrm{ha}^{-1}$ causou resultado superior às doses de $6 \mathrm{e}$ $12 \mathrm{t} \mathrm{ha}^{-1}$.

\section{LITERATURA CITADA}

ANDREOLI, C.V. Uso e manejo do lodo de esgoto na agricultura e sua influência em características ambientais no agrossistema. Curitiba,Universidade Federal do Paraná, 1999. 278p. (Tese de Doutorado)

ANDREOLI, C.V. \& PEGORINI, E.S. Gestão pública do uso agrícola do lodo de esgoto. In: Impacto ambiental do uso do lodo de esgoto. Jaguariúna, Embrapa - Meio Ambiente, 2000. p.281-312.

BARBOSA, G.M.C.; TAVARES FILHO, J. \& FONSECA, I.C.B. Avaliações de propriedades físicas de um Latossolo Vermelho eutroférrico tratado com lodo de esgoto por dois anos consecutivos. Sanare, 17:94-101, 2002b. 
BARBOSA, G.M.C.; TAVARES FILHO, J. \& FONSECA, I.C.B. Propriedades químicas de um Latossolo Vermelho eutroférrico após aplicação por dois anos consecutivos de lodo de esgoto. Acta Sci., 24:1501-1505, 2002a.

BISCAIA, R.C.M. \& MIRANDA, G.M. Uso de lodo de esgoto calado na produção de milho. Sanare, 5:86-89, 1996.

BRASIL, Secretaria Nacional de Defesa Agropecuária. Regras para análise de sementes. Brasília, 1980. 188p

DA ROS, C.O.; AITA, C.; CERETTA, C.A. \& FRIES, M.R. Lodo de esgoto: Efeito imediato no milheto e residual na associação aveia-ervilhaca. R. Bras. Ci. Solo, 17:257-261, 1993.

EMPRESA BRASILEIRA DE PESQUISA AGROPECUÁRIA EMBRAPA. Manual de métodos de análise de solo. 2.ed. Rio de Janeiro, 1997. 212p.

HIGGINS, A.J. Land application of sewage sludge with regard to cropping systems and pollution potencial. J. Environ. Qual., 13:441-448, 1984.

HORNICK, S.B. Crop production on waste amended gravel spoils. In: SOPPER, W.E.; SEAKER, E.M. \& BASTIAN, R.K., eds. Land reclamation and biomass production with municipal wastewater and sludge. University Park, Pensilvania State University Press, 1982. p.207-218.

LESSIN, C.W. \& GARCIA, W.J. Heavy metals in the food chain by translocation to crops grown on sludge - treated strip mine land. In: SOPPER, W.E. \& KERR, S.N., eds. Utilization of municipal sewage effluent and sludge on forest and disturbed land. University Park, Pensilvania State University Press, 1979. p.471-482.

LOURENÇO, R.S.; ANJOS, A.R.M. \& MEDRADO, M.J.S. Efeito do lodo de esgoto na produtividade de milho e feijão no sistema de produção de bracatinga. Sanare, 5:90-92, 1996.

LOURENÇO, R.S.; ANJOS, A.R.M. \& MEDRADO, M.J.S. Efeito do lodo de esgoto na produtividade de milho e feijão no sistema de produção de bracatinga. In: CONGRESSO BRASILEIRO DE CIÊNCIAS DO SOLO, 25., Viçosa, MG, 1995. Anais. Viçosa, MG, Sociedade Brasileira de Ciência do Solo/Universidade Federal de Viçosa, 1995. p.22732275 .

MARQUES, M.O. Incorporação de lodo de esgoto em solo cultivado com cana-de-açúcar. Jaboticabal, Universidade Estadual de São Paulo, 1996. 111p. (Tese Livre-Docência)

MELO, W.J.; MARQUES, M.O. \& SANTIAGO, G. Efeito das doses crescentes de lodo de esgoto sobre frações da matéria orgânica e CTC de um Latossolo cultivado com cana-de-açúcar. R. Bras. Ci. Solo, 18-449-455, 1994.
OLIVEIRA, F.C.; MARQUES, M.O.; BELLINGIERI, P.A. \& PERECIN, D. Lodo de esgoto como fonte de macronutrientes para a cultura do sorgo granífero. Sci. Agric., 52:360-367, 1995.

PEREIRA JR, A.B.; VALIM, M.C.A.; SOUZA, J.L. \& GONÇALVES, R.F. Utilização de lodo gerado em processo anaeróbio tipo tanque Imhoff como insumo agrícola para a cultura do milho (Zea mays L.). In: CONGRESSO BRASILEIRO DE ENGENHARIA SANITÁRIA E AMBIENTAL, 19., Foz do Iguaçu, 1997. Anais.Foz do Iguaçu, Associação Brasileira de Engenharia Sanitária e Ambiental, 1997. 398p.

RAPPAPORT, B.D.; MARTINS, D.C.; RENEAU JUNIOR, R.B. \& SIMPSON, T.W. Metal availability in sludge-amended soils with elevated metal levels. J. Environ. Qual., 17:4247, 1988.

SANEPAR. Manual técnico para utilização agrícola do lodo de esgoto no Paraná. Curitiba, 1997. 96p.

SILVA, F.C.; BOARETTO, A.E. \& BERTON, R.S. Características agrotecnológicas, teores de nutrientes e de metais pesados em cana-de-açúcar (soqueira), cultivada em solo adubado com o lodo de esgoto. In: CONGRESSO BRASILEIRO DE CIÊNCIAS DO SOLO. 25., Viçosa, MG, 1995. Anais.Viçosa, MG, Sociedade Brasileira de Ciência do Solo/ Universidade Federal de Viçosa, 1995. p.2279-2287.

SILVA, F.C.; BOARETTO, A.E.; BERTON, R.S.; ZOTELLI, H.B.; PEXE, C.A. \& MENDONÇA, E. Cana-de-açúcar cultivada em solo adubado com lodo de esgoto. Pesq. Agropec. Bras., 33:1-8, 1998.

SILVA, J.E.; RESCK, D.V.S. \& SHARMA, R.D. Alternativa agronômica para o biossólido produzido no Distrito Federal. Efeito na produção de milho e na adição de metais pesados em Latossolo no Cerrado. R. Bras. Ci. Solo, 26:487-495, 2002.

SILVA, J.E.; RESCK, D.V.S. \& SHARMA, R.D. Alternativa agronômica para o biossólido: A experiência de Brasília. In: Impacto ambiental do uso do lodo de esgoto. Jaguariúna, Embrapa Meio Ambiente, 2000. p.143-151.

STEVENSON, F.J. Humus chemistry: Genesis, composition, reactions. New York, J. Wiley \& Sons, 1982.

TEIXEIRA, D.V. Milho - superando limites de produtividade. Ano XXII, 2004. n.166. Disponível em: $<$ www.manah.com.br/informativos. asp?idI=9> Acesso em 20-4-2005.

TSUTIYA, M.T. Metais pesados: O principal fator limitante para o uso agrícola de biossólidos das estações de tratamento de esgotos. In: CONGRESSO BRASILEIRO DE ENGENHARIA SANITÁRIA E AMBIENTAL, 20., Rio de Janeiro,1999. Anais. Rio de Janeiro, ABES, 1999. p.753761. 